\title{
On the Use of Capsaicin as a Natural Preservative Against Fungal Attack on Pinus sp. and Hymenaea sp. Woods
}

\author{
Analine Crespo Ziglio, Débora Gonçalves* \\ Instituto de Física de São Carlos, Universidade de São Paulo-USP, \\ Av. Trabalhador São-Carlense, 400, CEP 13560-970, São Carlos, SP, Brazil
}

Received: March 19, 2013 ; Revised: August 5, 2013

\begin{abstract}
Capsaicin (capsicum oleoresin) extracted from two peeper species, Capsicum frutescens and Capsicum baccatum, was investigated as a natural preservative against fungal (Paecilomyces variotti) attack on Pinus sp. and Hymenaea sp. Static contact angle measurements were performed as a function of time in order to investigate the wetting properties of the wood samples treated with capsicum oleoresin. As revealed by X-ray diffraction analysis, photographs, and angle contact measurements, Hymenaea sp is more sensitive to the presence of capsicum oleoresin, which can inhibit, or retard, the growth of Paecilomyces variotti. Structures of filaments called hyphae, occurring typically in multicellular fungi, were observed on the sample surfaces studied by using an electronic scanning microscope. The capsicum oleoresin extracted from Capsicum frutescens showed to be more effective as a preservative due to its greater degree of pungency (higher capsaicin content) and better penetration into the cellular structure of the woods.
\end{abstract}

Keywords: peppers, wood preservatives, contact angles, surface properties, wettability

\section{Introduction}

Wood is a heterogeneous, highly complex polymeric material, with cellulose, hemicelluloses (or polyoses), and lignin as the main components of the cell walls of wood fibers ${ }^{1,2}$. Due to a natural resilience, wood has been widely used in different applications, and this property can be quantified by its ability to resist against harmful effects such as moisture, temperature, and fungal attacks; in this latter case, the rate of deterioration depends strongly on the local conditions (surface) ) $^{3,4}$. Frequently, the treatment used in order to protect wood is impregnation and coating with chemical preservatives. However, meanwhile sapwood can be completely impregnated with preservatives, yielding a relatively protected surface, heartwood has been keeping unprotected once it is less absorbent ${ }^{5}$.

The ability to resist degradation determines how it can be possible to classify the natural durability of wood (high, medium, and low resistant to agents of deterioration). Xylophagous organisms are able to degrade wood with time and under certain conditions by attacking the natural polymers of the cell walls, which act as sources of nutrition. Some fungi have a wide range of enzymes that are able to metabolize these natural polymers ${ }^{5}$, and deterioration of structural timber, for instance, may cause significant changes in the physical and chemical properties of wood ${ }^{6}$.

Assuming that many deterioration effects are harmful, and yield serious damage for wood products used in various applications, a proper treatment with preservatives is mandatory with the aim of increasing lifetime and surface quality. The presence of a chemical preservative deposited onto a wood surface implicates on a typical increase of durability and effectiveness against spoilage organisms?

*e-mail: gdebora@ifsc.usp.br
Traditionally, most widely used chemical preservatives are classified into two classes: oilborne preservatives, such as creosote and copper naphthenate; and waterborne preservatives, such as ammoniacal copper arsenate (ACA), acid copper chromate (ACC), chromated copper arsenate (CCA), and chromated copper borate $(\mathrm{CCB})^{8,9}$. However, despite the massive growth of production and consumption of preservatives from the wood products industries, when one takes into consideration both environment and health, there is great interest on the reduction of the use of preservatives based on heavy metals, which are toxic and persistent pollutants, in particular arsenic and chromium. Today, environmentally acceptable options include natural preservatives, since they are safer than synthetic ones for humans and environment, and do not leave residues in the environment. Here, we focused our research on the use of capsicum oleoresin extracted from two peppers, Capsicum frutescens and Capsicum baccatum, as an alternative, natural preservative against the attack of Paecilomyces variotti (soft-rot fungus) on Pinus sp. and Hymenaea sp. woods.

\section{Material and Methods}

Two species of wood were studied here, one of them is less resistant to fungal attacks, Pinus sp., than the other one, Hymenae sp. The wood samples were cut at $5.0 \times 3.0 \times 1.0 \mathrm{~cm}^{3}$, with controlled and stabilized humidity (0\%) following the normative procedures from NBR 7190:1997 (Norma Brasileira Regulamentadora, Associação Brasileira de Normas Técnicas) ${ }^{10}$. When the preservative treatment was considered, two pepper species were chosen: Capsicum frutescens and Capsicum baccatum. Among the species of fungus most suitable to compare decay rates, 
Paecilomyces variotti (soft-rot fungus) was chosen, and obtained from Institute Lauro de Souza Lima, Bauru, Brazil.

For obtaining the capsicum oleoresin, $250 \mathrm{~g}$ of commercially grown chili pepper (Capsicum frutescens or Capsicum baccatum) was added into a glass vessel containing $500 \mathrm{~mL}$ of ethanol (99.3\%). This mixture was divided into two airtight containers; one part (peppers in $250 \mathrm{~mL}$ of ethanol) was blended, infused for five days, and then, filtered. The residue obtained after the filtration step was placed in the second container with the remaining ethanol $(250 \mathrm{~mL})$. The process of blend, infusion, and filtration was repeated, and then, the solvent was removed by rotary evaporation ${ }^{11}$. These steps are illustrated in Figure 1.

The culture medium for Paecilomyces variotti was prepared by using a heated mixture of Sabouraud Dextrose Agar in $400 \mathrm{~mL}$ of boiling water. The culture medium was placed into an autoclave at $121{ }^{\circ} \mathrm{C}$ for $15 \mathrm{~min}$ and, then, deposited onto sterile Petri dishes under a laminar air-flow to avoid contamination. The woods cut at $5.0 \times 3.0 \times 1.0 \mathrm{~cm}^{3}$ had their surfaces totally recovered (painted) with $15 \mathrm{~mL}$ of the capsicum oleoresin. After that, the wood samples were left for $12 \mathrm{~h}$ in a dry chamber at room temperature. The fungus was inoculated on the wood surfaces by using sterile swabs previously deposited onto the Petri dishes containing the nutrient Agar; this procedure was realized under laminar air-flow to keep a condition of surface sterilization. Petri dishes containing the wood samples modified with capsicum oleoresin, without and with inoculated fungi, were kept at room temperature in a laminar air-flow cabinet, and photographed for periods of time in order to monitor the fungal growth. After four months, the wood samples were autoclaved at $121{ }^{\circ} \mathrm{C}$ for $15 \mathrm{~min}$ in order to remove the fungus and, therefore, sterilize the surfaces, disrupt the fungal growth, and then, allow further analysis.

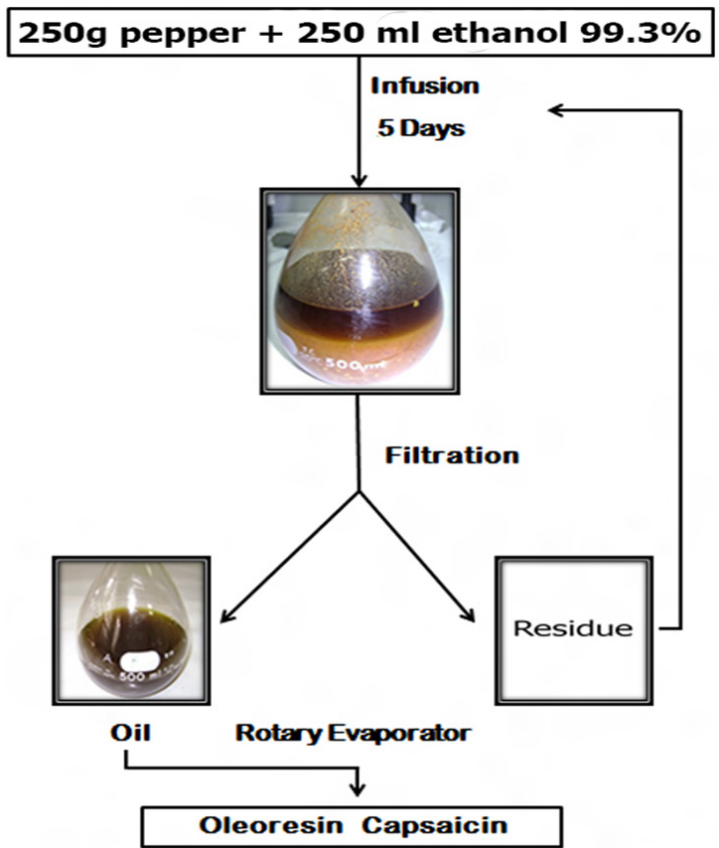

Figure 1. Procedure used to obtain from chili peppers (Capsicum frutescens or Capsicum baccatum).
Contact angle measurements were performed by using a homemade goniometer, which includes a metal rail, a webcam, and a commercial light source, which were adjusted aiming to allow a full alignment of the assembly inside a black chamber with no external light reflection. For these measurements, the samples were cut at $5.0 \times 3.0 \times 1.0 \mathrm{~cm}^{3}$ in the longitudinal direction, and the solvent was deionized water. For each sample, five drops of $8 \mu \mathrm{L}$ of water were deposited on its surface, and then, measured the contact angle for at least ten times on each position by using a free and open Java based image software, ImageJ. All sets of measurements were performed at $22{ }^{\circ} \mathrm{C}$ at about $45-55 \%$ relative humidity in the home-made, dark chamber containing the goniometer.

$\mathrm{X}$-ray diffraction measurements were performed by using a equipment with a tube voltage and current of $50 \mathrm{KV}$ and $100 \mathrm{~mA}$, respectively, and an angle of incidence scanned at $2^{\circ} \mathrm{min}^{-1}$.

A scanning electron microscope (SEM) was used in order to analyze the wood samples $\left(1.0 \times 1.0 \times 1.0 \mathrm{~cm}^{3}\right)$ modified with Capsicum fruntescens and inoculated fungus.

\section{Results and Discussion}

In order to study how Paecilomyces variotti grows on the surface of woods protected with capsaicin oleoresin, their biological deterioration were verified by means of photographs taken within a certain period of time, four months. Figure 2 shows the images for Pinus sp. (a) and

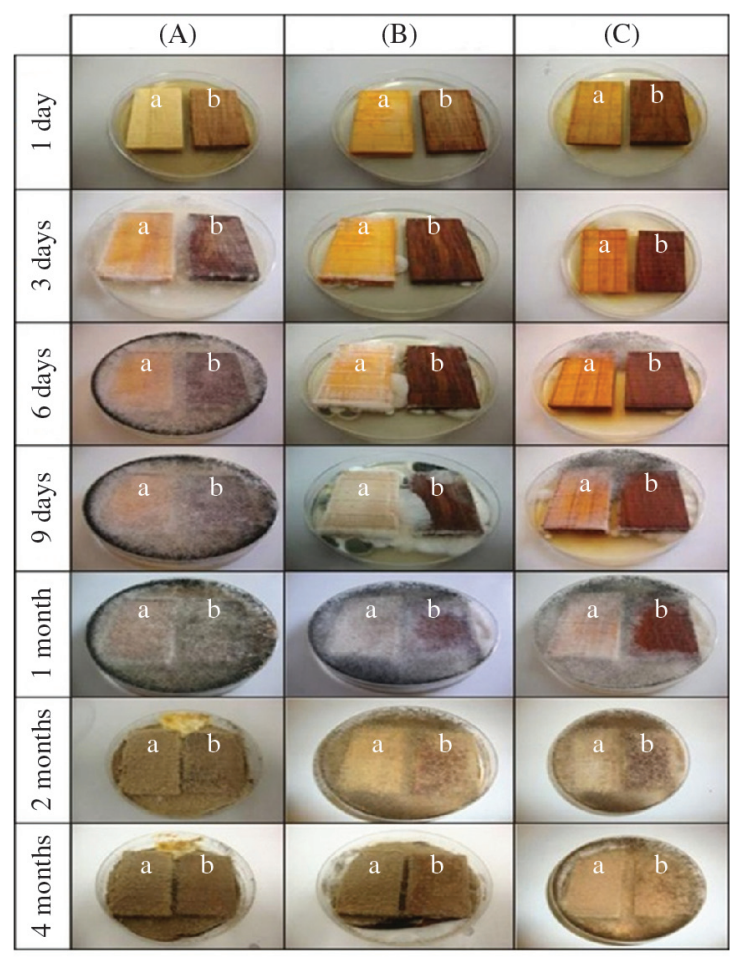

Figure 2. Images of the samples in nutrient agar without (A) and with the presence of oleoresin capsaicin extracted from Capsicum baccatum (B) and Capsicum frutensens (C); a) Pinus sp., b) Hymenae sp. 
Hymenae sp. (b) modified with inoculated fungus, in the absence of preservative (A), and after being modified with Capsicum baccatum (B), and Capsicum frutescens (C). These images indicate that four months is a period of time long enough to obtain samples completely covered with fungal hyphae. Besides, it is evident certain preferential spread of Paecilomyces variotti on the surfaces of Pinus sp. (letter $a$ in Figure 2), mainly because of a set of characteristics (low density, amounts of extractives, and chemical composition), which yields to Pinus sp. a low resistance to degradation occasioned by a pathogenic fungal growth. However, in the case of Paecilomyces variotti, a soft-rot fungus, the presence of lignin at high concentrations in softwoods such as Pinus sp. is a limiting factor, since soft-rot fungi have little effect on the degradation of lignin 7 .

Figure 2 also allows one to visualize a relatively rapid fungal growth (only after three days) for both Pinus sp. and Hymenae sp. without any preservative treatment. Furthermore, it can be noticed that Capsicum frutescens is more effective against fungal attacks than Capsicum baccatum.

Table 1 shows the values of contact angles obtained by using the sessile drop method ${ }^{12}$ for the samples before and after modifying with capsaicin oleoresin, following a treatment in a dry chamber at room temperature for $12 \mathrm{~h}$. The woods without any preservative treatment showed values of contact angles higher than those obtained for the samples after being modified with capsicum oleoresin. The results also indicated that the contact angles are smaller for Pinus sp. due to its lower wettability, that means a hydrophobic character, mainly due to characteristics such as chemical composition and low density.

After modifying the samples with capsicum oleoresin, it becomes evident that Capsicum frutescens yields greater wettability, i.e., lower contact angles for both Pinus sp. and Hymenaea sp. Therefore, one assumes that capsicum oleoresin penetrates into the wood structure, in particular for Pinus sp., providing a better protection against the fungal attack. After sterilization in an autoclave, the contact angles were measured again after two and four months, when it was verified that the surface wettability for these samples varied (reduced) or, in other words, they become more hydrophobic.

To verify possible changes in the crystallinity of the wood samples caused by the fungal growth, x-ray diffraction measurements were performed. No significant changes were noticed in the diffractograms for the samples modified either with Capsicum baccatum or Capsicum frutescens without inoculated fungus, and Figure 3 shows only the results obtained for the samples attacked by Paecilomyces variotti before and after being modified with Capsicum frutescens. Small shifts to lower values of $2 \theta$ for heat treated wood samples in dry and moist air have been related to an increase of the distance between fibers ${ }^{13}$. Generally speaking, Figure 3 evidences diffractograms that are close to each other, even when the samples were autoclaved at $121{ }^{\circ} \mathrm{C}$ in order to eliminate inoculated fungus. In fact, previous reports have indicated that treatments at temperatures lower than $140{ }^{\circ} \mathrm{C}$ rarely cause changes in the crystallinity of woods, in particular for short periods of time ${ }^{14}$, as we also verified here. The half-bandwidths of the peak at $2 \theta=22^{\circ}$ in Figure 3, in particular for Hymenaea sp., were measured, and gave an indication that Paecilomyces variotti would cause a structural reorganization of an amorphous matrix of lignin. Consumption and, subsequently, disruption of most important chemical bonds wood implicates on a loss of stability and periodicity, and yields broaden peaks in the diffractograms.

Figure 4 shows the images obtained by using a scanning electron microscope, where it is evident the presence of hyphae (black arrow) from Paecilomyces variotti even for a cleaned, autoclaved sample. It is well-known that hyphae may penetrate into the wood structures from cracks and pores, and move into the medullar rays, which contain a large supply of sugars, carbohydrates, proteins, and extractives ${ }^{15}$. Therefore, it is possible to evidence in the images from Figure 4 a process of fungal growth and small granules (white arrow), which are, in fact, residues of capsicum oleoresin. Figure $4 \mathrm{~b}$ shows cracks $(\sim 40 \mu \mathrm{m})$ and pores, which are not observed on the wood samples without surface treatment. Figure $4 \mathrm{c}$ suggests the presence of chlamydospores, which are thick-walled fungal spores into a brown cell wall, occurring in many groups of stain fungi. They are close to the pores, and although a round flat

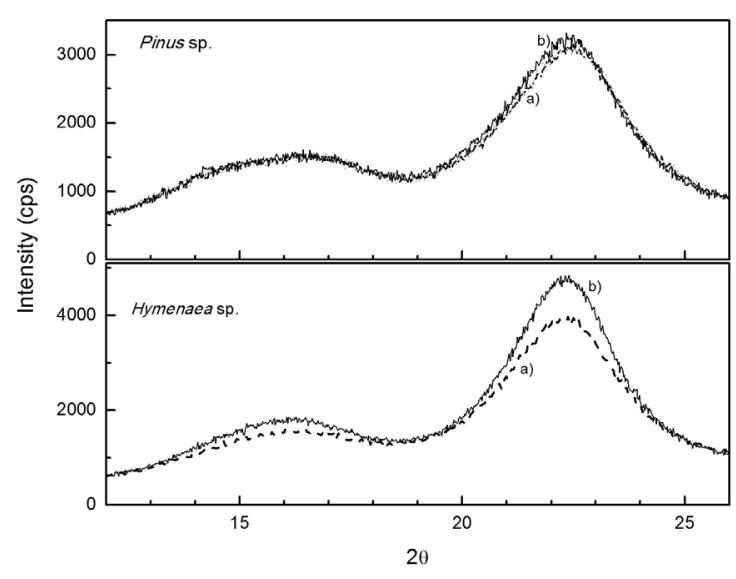

Figure 3. Diffractograms for Pinus sp. and Hymenaea sp. a) without any surface treatment (or inoculated fungus), and b) with oleoresin capsaicin and inoculated fungus.

Table 1. Contact angles for wood samples without and with preservative treatment*.

\begin{tabular}{|c|c|c|c|}
\hline $\begin{array}{ll}\text { samples } & \text { preservative }\end{array}$ & Absent & Capsicum baccatum & Capsicum frutescens \\
\hline Pinus sp. & $32^{\circ}$ & $19^{\circ}$ & $9^{\circ}$ \\
\hline Hymenaea sp. & $55^{\circ}$ & $41^{\circ}$ & $18^{\circ}$ \\
\hline
\end{tabular}

\footnotetext{
* measurement uncertainty: $3 \%$.
} 

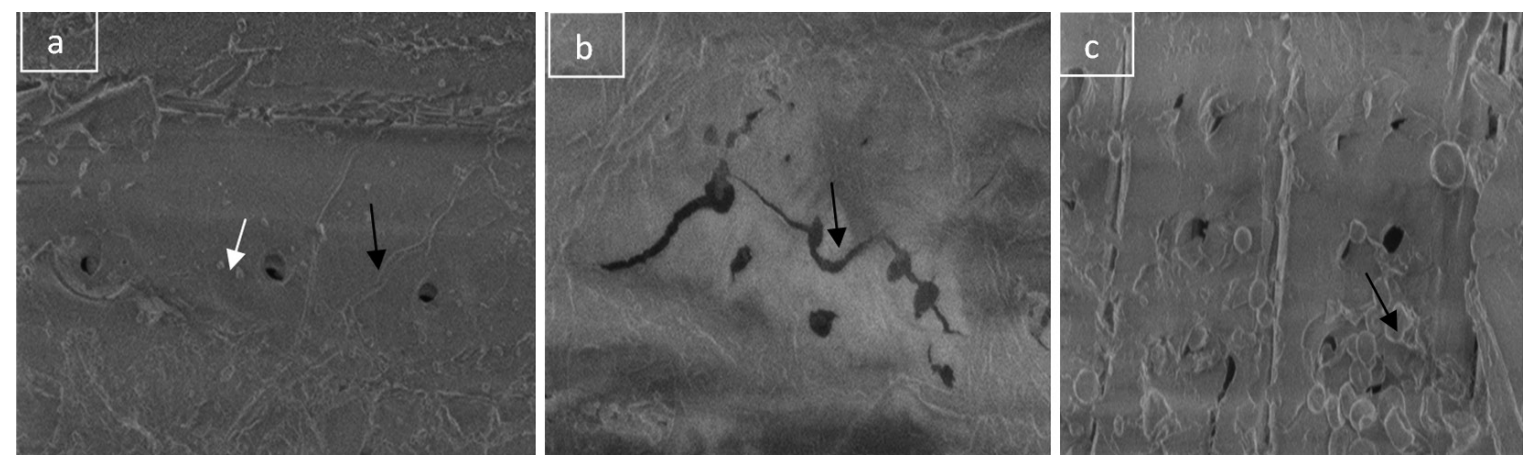

Figure 4. Photomicrographs obtained by SEM for the autoclaved wood samples evidencing the presence of: a) hyphae, open pores, and residues of oleoresin capsicum; b) cracks after fungal attack; c) chlamydospores.

shape cannot be clearly observed in these images (typically from hyphae, which is separated from the mother cell under stress - low humidity or food conditions, for instance), they start to behave as resistant spores, that means more resistant to heat, dryness, and preservatives, when compared to fungal mycelia.

\section{Conclusions}

Pinus sp. and Hymenaea sp. allowed the growth of Paecilomyces variotti, but, after treatment with capsaicin oleoresin, the fungal attack showed to be less effective. Contact angle measurements and photographs taken within a period of four months evidenced that Capsicum frutescens penetrates better into the wood structures, and it is more efficient for protecting the samples against decay organisms.

\section{References}

1. Brisolari A. Estudo da molhabilidade em madeiras tropicais ou de reflorestamento por medidas de ângulo de contato e de permeabilidade. [Dissertação]. São Carlos: Universidade de São Paulo; 2008.

2. Fromm J, Rockel B, Lautner S, Windeisen E and Wanner G. Lignin distribution in wood cell walls determined by TEM and backscattered SEM techniques. Journal of Structural Biology. 2003; 143:77-84. http://dx.doi.org/10.1016/S10478477(03)00119-9

3. Paes JB, Moraes VM and Lima CR. Resistência natural de nove madeiras do semiárido brasileiro a fungos xilófagos em condições de laboratório. Revista Árvore. 2004; 28(3):275-282. http://dx.doi.org/10.1590/S0100-67622004000200014

4. Chapin FS III, Zavaleta ES, Eviner VT, Naylor RL, Vitousek PM, Reynolds HL et al. Consequences of changing biodiversity. Nature. 2000; 405:234-242. PMid:10821284. http://dx.doi. org/10.1038/35012241

5. Oliveira AMF, Lelis AT, Lepage ES, Lopes GAC, Oliveira LCS, Cañedo MD et al. Agentes destruidores da madeira. In: Lepage ES, editor. Manual de preservação de madeiras. São Paulo: IPT; 1986. p. 99-278. PMid:3722834.

6. Zabel RA and Morrell JJ. Wood microbiology: decay and its preservation. San Diego: Academic Press; 1992. 474 p.

7. Lepage ES. Química da madeira. In: Lepage ES, editor. Manual de preservação de madeiras. São Paulo: IPT; 1986. v. 1.

8. Stumpp E, Rech V, Sattler MA, Barros NM and Abitante AL. Avaliação de sustentabilidade e eficácia de tratamentos
From the X-ray diffraction measurements, it was verified that Paecilomyces variotti causes a slight modification into the constituent fibers of the wood samples. Using a scanning electron microscope, it was verified an opening of the pore structure of the samples with cracks caused by fungi. Traces of hyphae and chlamydospores were noticed on the sample surfaces even after sterilization (fungus removal).

\section{Acknowledgements}

The authors acknowledge Fundação de Amparo à Pesquisa (FAPESP), Coordenação de Aperfeiçoamento de Pessoal de Nível Superior (CAPES), Conselho Nacional de Pesquisa $(\mathrm{CNPq})$, and Grupo de Biofísica do Instituto de Física de São Carlos (IFSC), Universidade de São Paulo (USP) for allowing us to obtain the fungal culture media.

preservantes naturais de madeiras de florestas plantadas no RS para o controle do cupim. Ambiente Construído. 2006; 6:21-31.

9. Schultz TP and Nicholas DD. Development of environmentallybenign wood preservatives based on the combination of organic biocides with antioxidants and metal chelators. Phytochemistry. 2002. 61:555-560. http://dx.doi.org/10.1016/ S0031-9422(02)00267-4

10. Associação Brasileira de Normas Técnica - ABNT. NBR 7190: Projeto de estruturas de madeira. Rio de Janeiro; 1997.

11. Gonzáles MM, Lara FM, Carbajal GG and Flota FV. Capsaicinoid quantitation by in situ densitometry of thin layer chromatography plates. Journal of Liquid Chromatography et Related Technologies. 2007; 30:1697-1704. http://dx.doi. org/10.1080/10826070701225041

12. Soares AC, Oliveira RM, Brisolari A, Sales A and Gonçalves D. Molhabilidade em amostras de Araucaria angustifolia e Pinus elliottii após tratamento térmico e envelhecimento. Scientia Forestalis. 2011;39:447-456.

13. Bhuiyan MTR, Hirai N and Sobue N. Changes of crystallinity of wood cellulose by heat treatment under dried and moist conditions. Journal of Wood Science. 2000; 46:341-436. http:// dx.doi.org/10.1007/BF00765800

14. Oliveira RM. Utilização de técnicas de caracterização de superfícies de madeiras tratadas termicamente. [Tese]. São Carlos: Instituto de Física de São Carlos, Universidade de São Paulo; 2009.

15. Schmidt O. Wood and tree fungi. Berlin: Springer; 2006. 15 p. 